\title{
Application of cDNA Arrays to Monitor mRNA Profiles in Single Preimplantation Mouse Embryos
}

BioTechniques 33:376-385 (August 2002)

\author{
T. Brambrink, P. Wabnitz ${ }^{1}$, R. \\ Halter $^{2}$, R. Klocke', J. Carn- \\ wath, W. Kues, C. Wrenzycki, \\ D. Paul ${ }^{2}$, and H. Niemann \\ Institute for Animal Science \\ (FAL), Neustadt, ${ }^{1}$ Ingenium \\ Pharmaceuticals AG, Martins- \\ ried, and ${ }^{2}$ Fraunhofer Institut \\ fuer Toxikologie und Aerosol- \\ forschung, Hannover, Germany
}

\section{ABSTRACT}

Array technology is a widely used tool for gene expression profiling in various biological systems. However, the application of this method to mammalian preimplantation embryos is limited by the small amount of mRNA that can be extracted from a single embryo, which is not sufficient for array analysis. Here we report a protocol for the rapid global amplification of embryonic mRNA that permits the generation of expression profiles from single murine blastocysts. The approach combines global PCR and T7 RNA polymerase amplification and allows the preparation of labeled, amplified RNA for array hybridization from single murine blastocysts containing approximately $1.5 \mathrm{pg}$ mRNA in less than $12 \mathrm{~h}$. We demonstrate that this amplification procedure is highly reproducible and does not bias original relative $m R N A$ levels. Signal patterns from various embryonic stages of murine development revealed marked differences in mRNA expression that were in accordance with previously published data. We found genes known to be involved in em bryonic apoptosis expressed at different levels in individual murine day 3.5 blastocysts. This technique can thus be used to assess embryonic viability and investigate molecular mechanisms of embryonic development.

\section{INTRODUCTION}

DNA array technology provides the possibility of monitoring quantitatively expression levels of an essentially unlimited number of genes (25). However, standard array analysis protocols typically employ microgram quantities of poly(A) RNA to achieve satisfactory signal intensity $(1,3,5,8,9,15,16,22)$. Murine preimplantation blastocysts obtained $94 \mathrm{~h}$ after hCG application typically consist of 32 cells and contain only about $1.5 \mathrm{pg}$ mRNA $(11,20)$. This tiny amount of starting material has to be globally amplified to generate expression profiles from single preim plantation embryos. The maintenance of the original relative levels of mRNA species during this amplification is crucial to obtain reliable data.

Recently, procedures for the global amplification of mRNA by in vitro transcription have been reported that employ a poly(dT) primer with a T7 RNA polymerase promoter sequence at its $5^{\prime}$-end to prime the reverse transcription of mRNA $(6,19,21,24,27)$. The cDNA obtained can be transcribed by T7 RNA polymerase, yielding amplified antisense RNA. The limiting factor of the in vitro transcription reaction is the binding of the enzyme to its recognition sequence, which allows all cDNAs containing the same promoter to be amplified at nearly the same rate. The limitation of this technique is the low amplification performance of T7 in vitro transcription reactions. The preparation of labeled, amplified RNA in sufficient amounts from single embryos would require multiple rounds of reverse and in vitro transcription and therefore take several days (24).

PCR provides the amplification performance required. However, in PCR, different products amplify at different rates when primed with sequence-specific primers attributed to different, primer-specific annealing efficiencies (17). Thus, relative amounts of mRNA species are not maintained during PCR amplification that employs sequencespecific primers. The global PCR approach eliminates primer-specific effects because all mRNA molecules obtained from a biological sample are converted into cDNA molecules that contain short universal anchor sequences at both ends $(2,12,26,32)$. All different cDNAs derived from the mRNA sample can therefore be amplified by a universal primer pair. This avoids the bias from the relative amounts of different product species. Performing only a low number of cycles in a global PCR further minimizes the resulting bias in relative product amounts. However, this is associated with the problem that only insufficient quantities of amplified material can be synthesized (17).

The approach of this study was to combine the benefits of both of these amplification techniques to create a procedure that is sensitive, fast, and reliable. A global PCR step with a small number of cycles before a single round of in vitro transcription permits the reproducible amplification of complex mRNA sam ples, with the vast majority of original relative mRNA levels not being biased. We report the successful development of a technique that permits the analysis of relative mRNA levels in single embryos, thus providing a complex insight into individual transcriptional activities. This amplification technique can be applied to all eukaryotic samples whether of known or unknown genomic sequence and is suitable for use with homemade and commercially available arrays. 
To comply with the terms commonly used in cDNA array technology, "probe" refers to the DNA molecules immobilized on the array surface, while "target" refers to the RNA molecules in the hybridization solution.

\section{MATERIALS AND METHODS}

\section{Embryo Production}

Murine embryos were obtained from CD2F1 females superovulated by intraperitoneal injection of $10 \mathrm{U}$ eCG (Intergonan $^{\mathrm{TM}}$; Intervet, Unterschleißheim, Germany), followed by the injection of 10 U hCG (Primogonyl ${ }^{\mathrm{TM}}$; Schering, Berlin, Germany) 48 h later. Metaphase II-arrested eggs were collected $20 \mathrm{~h}$ after hCG application from unmated donors. Embryonic stage donors were mated with CD2F1 males, two-cell stages were collected $48 \mathrm{~h}$ after mating, and blastocysts were collected $94 \mathrm{~h}$ after hCG application. Embryos were washed three times in PBS supplemented with $0.1 \%$ polyvinyl alcohol, snap-frozen in liquid nitrogen, and stored at $-80^{\circ} \mathrm{C}$.

\section{RNA Extraction}

Template mRNA from pooled or single embryos was obtained by Dynabead $^{\mathrm{TM}}$ (Dynal AS, Oslo, Norway) oligo-d(T) extraction. Immediately after the removal of the embryos from the $80^{\circ} \mathrm{C}$ freezer, $20 \mu \mathrm{L}$ lysis/binding buffer were added, and the samples were processed according to the manufacturer's protocol with the following modification: the beads were washed once with washing buffer $A$ and three times with washing buffer B before the elution of mRNA was performed at $65^{\circ} \mathrm{C}$ in $11 \mu \mathrm{L}$ RNase-free water.

RNA from CD2F1 kidney tissue was purified by RNeasy ${ }^{\mathrm{TM}}$ (Qiagen $\mathrm{GmbH}$, Hilden, Germany) extraction, according to the manufacturers protocol. Oligotex ${ }^{\mathrm{TM}}$ mRNA extraction (Qiagen $\mathrm{GmbH}$ ) of total RNA yielded mRNA. From this mRNA, amounts equivalent to $5 \mathrm{ng}$ total RNA were used for the evaluation of the amplification technique.

\section{First-Strand Synthesis}

One microliter of $20 \mu \mathrm{M} \mathrm{T} 7 \mathrm{p}-\mathrm{d}(\mathrm{T})_{21}$
Primer (5'-TCTAGTCGACGGCCAG TGAATTGTAATACGACTCACTATA GGGCGTTTTTTTTTTTTTTTTTTT-

TT-3') was added to the eluted template mRNA, and the samples were denatured by a 2-min incubation at $70^{\circ} \mathrm{C}$. Samples were immediately placed on ice for $1 \mathrm{~min}$, and then $8 \mu \mathrm{L}$ mastermixture were added, consisting of $2 \mu \mathrm{L} 10 \times$ PCR buffer (Applied Biosystems, Foster City, CA, USA), 5 mM $\mathrm{MgCl}_{2}$ (Invitrogen, Karlsruhe, Germany), $2 \mu \mathrm{L}$ dNTP solution (Amersham Biosciences), $1 \mu \mathrm{L}$ RNasin ${ }^{\circledR}$ (Applied Biosystems), and $1 \mu \mathrm{L}$ MuLV reverse transcriptase (Applied Biosystems). The samples were incubated at $30^{\circ} \mathrm{C}$ for 5 min for primer annealing, followed by incubation at $42^{\circ} \mathrm{C}$ for $1 \mathrm{~h}$ for the reverse transcription of the template mRNA. The samples were then heated to $70^{\circ} \mathrm{C}$ for $10 \mathrm{~min}$ to degrade the tem plate RNAs.

\section{Second-Strand Synthesis}

For second-strand synthesis, $50 \mu \mathrm{L}$ $2 \times$ DOP-PCR buffer (Roche Diagnostics, Penzberg, Germany), $1 \mu \mathrm{L}$ degenerate oligonucletide primer (5'-CCGACTCGAGNNNNNNATGTGG-3'; Roche Diagnostics), and $23.5 \mu \mathrm{L}$ water were added to each $20-\mu \mathrm{L}$ reverse transcriptase sample. Samples were heated to $95^{\circ} \mathrm{C}$ for $5 \mathrm{~min}$ and then incubated at $30^{\circ} \mathrm{C}$ for $2 \mathrm{~min}$. After the addition of 5 IU Taq DNA polymerase (Invitrogen), the samples were heated at a rate of $0.2^{\circ} \mathrm{C} / \mathrm{s}$ to $72^{\circ} \mathrm{C}$ and incubated at $72^{\circ} \mathrm{C}$ for $3 \mathrm{~min}$.

\section{Global PCR}

After second-strand synthesis was completed, $2.5 \mu \mathrm{L}$ each $\mathrm{T} 7 \mathrm{p}-\mathrm{d}(\mathrm{T})_{21}$ primers and degenerate oligonucleotide primers were added. Twenty-five PCR cycles were performed as follows: cDNA was denatured at $94^{\circ} \mathrm{C}$ for $30 \mathrm{~s}$, and primer annealing was performed at $60^{\circ} \mathrm{C}$ for $30 \mathrm{~s}$, followed by an elongation step at $72^{\circ} \mathrm{C}$ for $4 \mathrm{~min}$.

\section{Purification and Concentration}

PCR products were purified using the GFX-PCR DNA purification kit (Amersham Biosciences), according to the manufacturer's protocol, eluted in 
$75 \mu \mathrm{L} 0.1 \times$ TE buffer (10 mM Tris$\mathrm{HCl}, \mathrm{pH} 8.0$, 1 mM EDTA), and volumes were adjusted to $12 \mu \mathrm{L}$ by vacuum centrifugation.

\section{In Vitro Transcription and Labeling}

After the addition of $2 \mu \mathrm{L} 10 \times$ rxn buffer, $2 \mu \mathrm{L}$ each ATP, CTP, GTP, and UTP (100 mM), $2 \mu \mathrm{L}$ DTT, and $2 \mu \mathrm{L}$ T7 RNA polymerase (T7 Ampliscribe $^{\mathrm{TM}}$; Epicentre, Madison, WI, USA), in vitro transcription was performed at $42^{\circ} \mathrm{C}$ for $3 \mathrm{~h}$, followed by DNase I digestion at $37^{\circ} \mathrm{C}$ for $15 \mathrm{~min}$. Amplified RNA was purified using RNeasy Mini Kit, and $2 \mu \mathrm{g}$ of the RNA obtained were directly labeled with DIG-Chem-Link Reagent (Roche Diagnostics) and immediately added to the hybridization buffer.

\section{Array Production}

Eighty-six murine cDNA probes plus 10 control probes were spotted onto a nylon membrane (Hybond ${ }^{\circledR} \mathrm{N}$; Amersham Biosciences). A BLAST search was performed for every cloned probe sequence to confirm absence of homology to other known gene sequences. Probe cDNAs were cloned into pGEM $^{\circledR}$-T easy vector (Invitrogen) and re-amplified from this vector by PCR using T7 (5'-ACTCACTATAGGGCG AATTG-3') and SP6 (5'-ATTTAGGTGACACTATAGAATACTC-3') standard primers. After PCR amplification, vector cloning sites were removed by EcoRI digestion. Gel electrophoresis was performed, and specific bands were extracted from the gel using the GFXPCR DNA purification kit. The volumes of the purified cDNA samples were adjusted to $8 \mu \mathrm{L}$ by vacuum centrifugation. The samples were denatured by the addition of $0.4 \mathrm{M} \mathrm{NaOH} / 10 \mathrm{mM}$ EDTA, and each probe was spotted twice onto a Hybond $\mathrm{N}$ membrane after $30 \mathrm{~min}$ incubation at room temperature. The probes were bound to the membrane by UVcross-linking.

\section{Hybridization and Detection}

Array membranes were prehybridized for at least $30 \mathrm{~min}$ with $10 \mathrm{~mL}$ prehybridization buffer, consisting of 9 mL High SDS buffer [7\% (w/v) SDS,
$0.1 \% \mathrm{~N}$-lauroylsarcosine, $50 \mathrm{~mL}$ deionized formamide, $25 \mathrm{~mL} 20 \times \mathrm{SSC}, 5 \mathrm{~mL}$ sodium phosphate buffer, $\mathrm{pH}$ 7.0, 20 $\mathrm{mL}$ water], and $1 \mathrm{~mL} 10 \times$ blocking solution (Roche Diagnostics). To saturate nonspecific binding sites, $5 \mu \mathrm{g}$ linearized pGEM-T easy vector were added. After adding the labeled target RNA, the arrays were hybridized overnight at $54^{\circ} \mathrm{C}$. After two washes for 5 min at room temperature with $2 \times \mathrm{SSC}$ and $0.1 \% \mathrm{SDS}$, the arrays were washed twice for $15 \mathrm{~min}$ at $55^{\circ} \mathrm{C}$ with $0.1 \times \mathrm{SSC}$ and $0.1 \%$ SDS. DIG-labeled molecules were detected, according to the manufacturer's protocol, with DIG-antibodyconjugated alkaline phosphatase and CSPD $^{\circledR}$ reagent (Tropix, Bedford, MA, USA). The arrays were exposed to Bio$\max ^{\mathrm{TM}}$ ML film (Eastman Kodak, Rochester, NY, USA) for $15 \mathrm{~min}$, and the films were developed according to standard procedures.

\section{Data Normalization and Processing}

Biomax images were digitalized using a charge-coupled device (CCD)

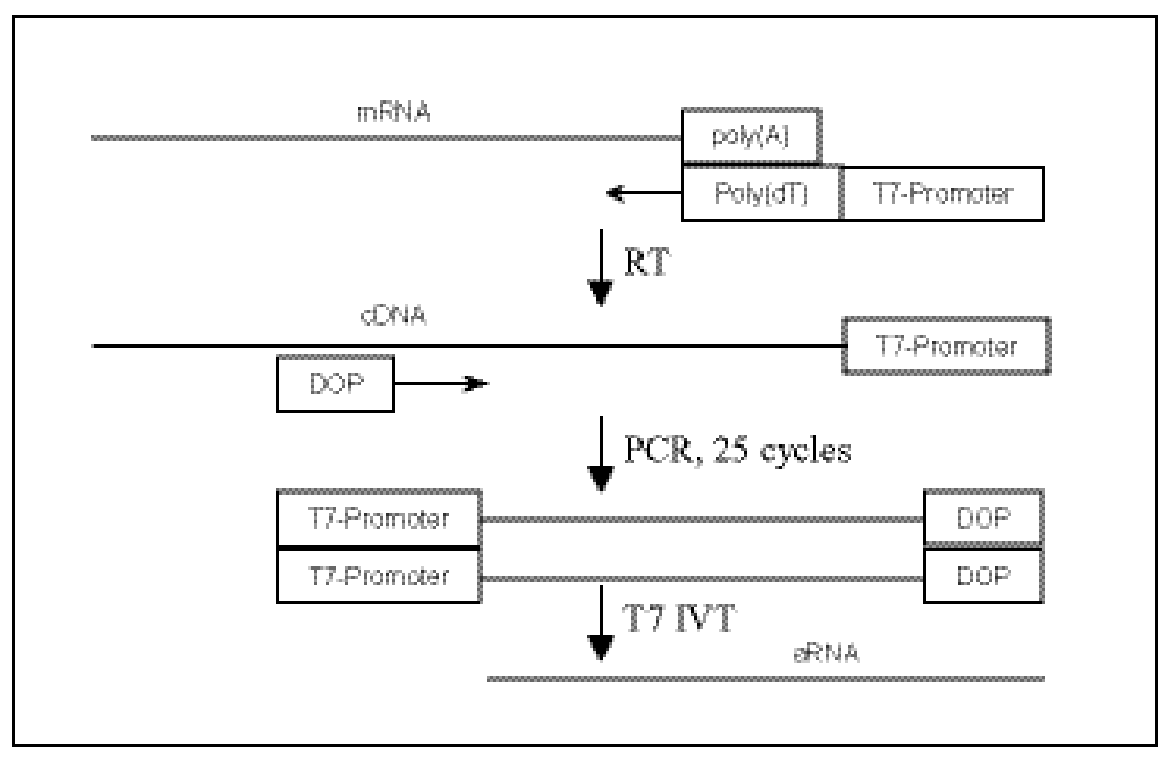

Figure 1. Scheme of the amplification procedure. First-strand cDNA synthesis by reverse transcription is primed with a poly(dT) primer containing a T7 promoter sequence. After the denaturation of the template mRNA, the second strand is synthesized in the first PCR cycle by Taq DNA polymerase. It is primed with a degenerate oligonucleotide primer at $30^{\circ} \mathrm{C}$, yielding dsDNA that can be further amplified in a global PCR with degenerate oligonucleotide primers and T7 poly(dT) primers. The pre-amplified cDNA is then used as a template for in vitro transcription, resulting in amplified antisense RNA. DOP, degenerate oligonucleotide primer; RT, reverse transcription; T7 IVT, T7 in vitro transcription; and aRNA, amplified RNA.

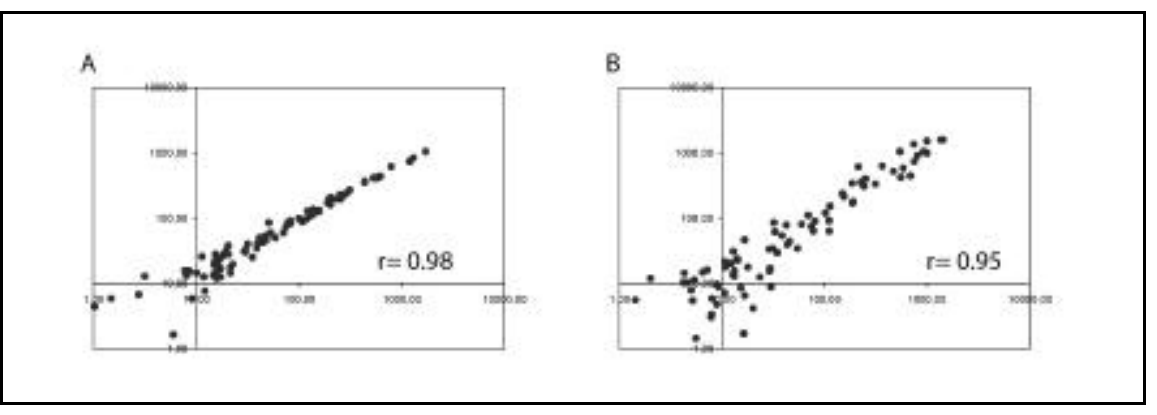

Figure 2. Reproducibility of the amplification procedure. (A) Scatter plot (log) of two samples that were separately amplified from a pool of two murine blastocysts. The relative signal intensities of one sample were plotted against corresponding signal intensities of the second sample after normalization. (B) Scatter plot (log) of two of five samples that were separately amplified from a pool of five murine blastocysts. Displayed are the best and the worst correlated data sets that we found in our reproducibility experiments. r, Pearson's correlation coefficient. 
camera (Quantix; Photometrix Ltd., Munich, Germany), and signal intensities were measured as background-corrected volumes by densitometry using IP Lab ${ }^{\mathrm{TM}}$ software (Signal Analytics, Vienna, Austria). To compensate for experimental variability, signal data were normalized employing array overall signal intensity and GAPDH as internal standards. A cut-off value was calculated to determine positive and negative values by employing the avercontrol spots plus twice their standard deviation. The correlation between data sets was analyzed by calculating the Pearson's correlation coefficient (28). Data are presented as mean correlation coefficient \pm SD. age signal intensities of four negative

\section{RESULTS}

Our approach was to increase the sensitivity of the T7 in vitro transcription amplification technique by performing a global PCR before a single round of in vitro transcription. The critical step is to convert the mRNA obtained from the embryo into cDNA containing a $\mathrm{T} 7$ promoter sequence necessary for subsequent $\mathrm{T} 7$ in vitro transcription and thus can be amplified by universal primers. This is achieved by using an oligo-d(T) primer carrying a T7 promoter sequence at its $5^{\prime}$-end for first-strand synthesis and the introduction of a universal oligonucleotide sequence at the opposite end of the cDNA by using a degenerate oligonucleotide
(A)

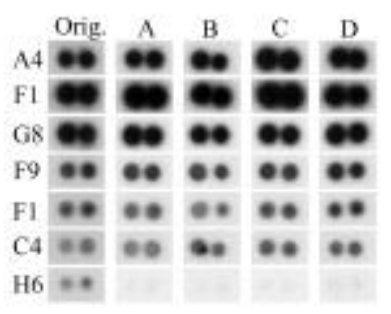

(B)

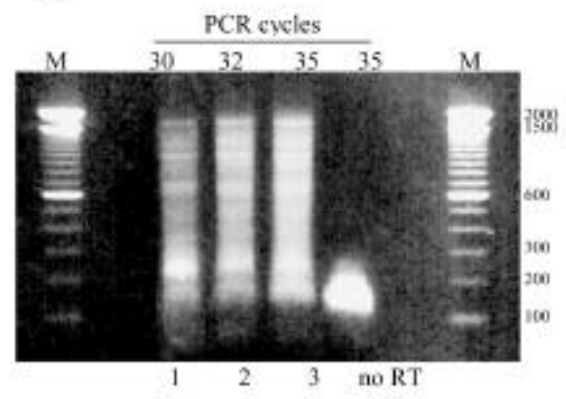

Figure 3. Signal representation and cDNA length after amplification. (A) Signals obtained from nonamplified (Orig.) and amplified (lanes A-D) kidney tissue mRNA. The latter was generated from aliquots equivalent to $5 \mathrm{ng}$ total RNA that were separated from the original sample. Coordinates on the left side index the position of the signals displayed on our model array according to Figure 4. Raw signal intensities were accurately represented in most of the probes on the array. In contrast, amplification led to the loss of the signal in some probes (e.g., H6). This is a telomerase clone (GenBank ${ }^{\circledR}$ accession no. AF073311). The probe is complementary to the sequence 143-417 on the 3.4-kb mRNA and is therefore not compatible with the amplification procedure. (B) PCR products obtained from three single embryos were visualized after performing different numbers of PCR cycles.
(A)

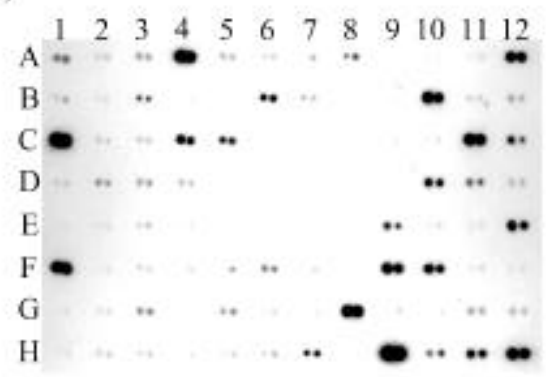

(B)

\begin{tabular}{|c|c|c|}
\hline A) & : apaf1 & $\mathrm{c}=68 \%$ \\
\hline A4 & : $\mathrm{\beta}$-actin & $\mathrm{cV}=5 \%$ \\
\hline A8 & bclx & $\mathrm{c}=82 \%$ \\
\hline$A_{12}$ & :caspase 3 & $\mathrm{cv}=4 \%$ \\
\hline 83 & $: \operatorname{cdc} 2$ & $c v=45 \%$ \\
\hline 810 & ; cyclinD1 & $c v=3 \%$ \\
\hline $\mathrm{Cl}$ & : daxx & $c v=17 \%$ \\
\hline $\mathrm{C} 11$ & : mdm2 & $\alpha=14 \%$ \\
\hline E12 & :tgl- $\beta$-receptor & $c v=10 \%$ \\
\hline$F 1$ & : ubiquitin & $c v=7 \%$ \\
\hline G8 & : GAPOH lused as & tandard) \\
\hline
\end{tabular}

Figure 4. Gene expression profile of a single day 3.5 blastocyst. (A) Digitalized picture of a typical cDNA array pattern obtained from a single embryo. (B) The cvs are displayed for a number of genes to measure the consistency of their expression among a group of embryos. The CV value is the standard deviation of the signals obtained from a group of embryos in one probe spot expressed as a percentage of the mean signal value in the group. Table 1 displays the primer sequences of the relevant cDNA probes. primer for second-strand synthesis (Figure 1). After 25 cycles of global PCR and a single round of T7 in vitro transcription, we obtained $10-15 \mu \mathrm{g}$ amplified RNA from a single embryo.

\section{Reproducibility}

To assess the reproducibility of the amplification procedure, mRNA extracted from a pool of five blastocysts was reverse-transcribed, and five autonomous amplification reactions were performed from the reverse transcription sample. Arrays from these samples were analyzed and compared. The average Pearson's correlation coefficient was calculated to be $0.97 \pm 0.02$. In additional experiments, two blastocysts were pooled, and two autonomous am plification reactions were performed (three repeats). The signal data sets obtained from these samples showed an average Pearson's correlation coefficient of $0.97 \pm 0.01$ (Figure 2).

\section{Signal Representation}

To test if relative amounts of mRNA species were maintained throughout the global amplification procedure, we compared samples amplified from mRNA amounts equivalent to $5 \mathrm{ng}$ mouse kidney total RNA to original (non-amplified) mouse kidney mRNA from the same source. Data generated from $2 \mu \mathrm{g}$ amplified RNA showed an average Pearson's correlation coefficient of $0.95 \pm 0.02$ when compared to those generated from $2 \mu \mathrm{g}$ original kidney mRNA (four repeats). We found that few probes (4 of 86) consistently gave false-positive or false-negative signals. As false-positive and false-negative signals were always observed in the same positions on the array, the corresponding probes were considered to be incompatible with the amplification procedure, and data obtained from these probes were excluded from further processing (Figure 3A).

\section{Effect of Probe Position on Signal Representation}

Arbitrary priming of second-strand synthesis implicates the loss of $5^{\prime}$ mRNA sequences during cDNA synthesis. The lengths of the global PCR 


\section{Research Report}

products were visualized after the gel electrophoretic separation of three samples amplified from single mouse blastocysts. However, after 25 PCR cycles, no PCR products were detectable, and, thus, another 5-10 cycles were performed for this experiment. Three individual amplification reactions of single murine blastocysts with different cycle numbers yielded a smear ranging from $200 \mathrm{bp}$ to $2 \mathrm{~kb}$, indicating that long mRNA molecules might have been truncated (Figure 3B). Therefore, it was suggested that a probe sequence should be cloned from the $3^{\prime}$-end of the mRNA molecule as opposed to the $5^{\prime}$-end to be successfully used in the analysis of am plified samples.

We compared two different sets of probes for array production to assess the effects of probe position on signal representation after amplification. In one set, the probe sequences cloned from the $5^{\prime}$-end of the corresponding
mRNA were used as probes, whereas in the second set, probe position was not taken into account during the cloning procedure. We compared the array data from original mouse kidney mRNA to samples that were amplified from amounts equivalent to $5 \mathrm{ng}$ total RNA derived from the same source. Signal representation was much better in the set of probes not selected for position (average Pearson's correlation coefficient of $0.95 \pm 0.02$; four repeats), and amplified samples generated more false-negative signals in probes positioned close to the $5^{\prime}$-end of the corresponding mRNA (average Pearson's correlation coefficient of $0.81 \pm 0.04$; two repeats). No clear cut-off distance was found; however, from our experimental data, we propose that probe sequences more than $2 \mathrm{~kb}$ away from the poly(A) tail of the corresponding mRNA are most likely not compatible with this amplification procedure.

\section{Embryonic Expression Profiling}

Expression profiles were generated from five single murine day 3.5 blastocysts and one pool of 10 murine day 3.5 blastocysts. The mean correlation coefficient of the data sets obtained from five single blastocysts was $0.91 \pm 0.05$ when compared to each other, whereas the mean correlation coefficient of these data sets was calculated to be $0.91 \pm$ 0.02 when compared to the data set obtained from the pooled blastocysts. We found $23 \pm 2$ of the array probes to be positive in single blastocyst analysis, and 26 of the cDNA probes to be positive in the pool of blastocysts.

The probes for $\beta$-actin, caspase 3 , cyclinD, tgf- $\beta$-receptor, daxx, $\operatorname{mdm} 2$, and ubiquitin gave similar relative signal intensities in all embryos tested, whereas the probes for cdc2, apaf1, and bclx showed highly variable relative signal values among the embryos 
(Table 1 and Figure 4). Positive apaf1 signals were detected in two of the embryos tested, and negative signal values were found in the remaining three embryos. The bclx probe gave a strong signal in one of the embryos but negative signal values in the remaining four embryos. The apaf1 and bclx probes were positive in the pool of blastocysts.

Furthermore, in one replicate expression profile from pools of 10 metaphase II-arrested eggs, two-cell stages and blastocysts (10 of each) were compared, and marked differences in the signal patterns obtained from these developmental stages were observed (Figure 5). The relative signal intensity obtained in the $\beta$-actin probe increased by a factor of 7.6 from the metaphase II-arrested egg to the blastocyst stage. The cDNA probe for cyclinE gave only very weak relative signals in metaphase II-arrested eggs and blastocysts, whereas a moderate rela- tive signal intensity was detected in the two-cell stages.

\section{DISCUSSION}

Results of the present study demonstrate that it is possible to generate informative expression profiles from single preimplantation embryos. The evaluation of the procedure employed for the representative amplification of embryonic mRNA revealed that this method works reliably on single blastocysts and minute amounts of tissue-derived total RNA. Thus, it could also be useful for the analysis of any other small eukaryotic sample.

The main advantage of the protocol presented here over conventional am plification procedures employing $\mathrm{T} 7$ in vitro transcription or PCR alone is the increase in sensitivity combined with a significant decrease in the time required for target preparation. Moreover, the data obtained with this technique are highly reproducible. For the first time, cDNA array expression profiles were generated from single murine preim plantation embryos. We were able to yield $10-15 \mu \mathrm{g}$ amplified RNA from a single day 3.5 murine blastocyst, typically containing about $1.5 \mathrm{pg}$ mRNA (20). Because standard hybridization protocols recommend the use of only 1-2 $\mu \mathrm{g}$ labeled message-derived material, it may be possible to further decrease the number of cells required.

The most critical point in amplifying samples for gene expression profiling is the maintenance of the relative amounts of mRNA species that characterize the original sample. Because nucleic acid extraction and enzymatic manipulation steps are thought to bias relative nucleic acid levels (24), the number of such steps should be minimized. This was achieved by perform 
ing only one round of in vitro transcription and replacing the enzymatic labeling of amplified RNA employing a reverse transcription reaction with a chemical labeling procedure.

To avoid signal loss after sample amplification, it is important to consider the position of the probe in the corresponding mRNA sequence. As this method preferentially amplifies sequences close to the poly(A) tail of mRNA molecules, only such sequences should be used as array probes. This has to be taken into account when selecting the optimal system for the analysis of amplified samples with commercially available arrays.

The expression data obtained from pools of different embryonic developmental stages can be correlated to reports in which the low relative abundance of $\beta$-actin mRNA in murine metaphase II-arrested eggs and a strong increase of relative $\beta$-actin mRNA abundance during development to the blastocyst stage have been previously described $(4,18,23)$. Furthermore, the onset of cyclinE mRNA transcription during the two-cell stage and a decrease in relative signal intensity during the blastocyst development have also been previously described (4). However, the increase of $\beta$-actin mRNA observed in the pool of two-cell stage embryos differs from previously published data (4). This might be due to the preferential use of late two-cell stages in which the em bryonic genome had already been switched on. In this study, it should be taken into account that only a single pool of each embryonic stage was analyzed.

Expression profiles of single murine blastocysts revealed one group of cDNA probes that showed consistent signal intensities in all analyzed em bryos. This group included the housekeeping gene probes and some cell cycle-related gene probes. The probes for apoptosis-related genes apaf1 and bclx showed increased relative signals in some embryos. In contrast, other probes for the genes involved in the regulation of apoptosis, caspase 3, daxx, and mdm 2 gave strong signals in all of the embryos tested. It is known that in mice and other mammalian species, a high proportion of preimplantation em bryos that develop to blastocysts contain apoptotic cells. Whether this is as-
Table 1. Primer Sequences of the cDNA Probes Described in Figure 4

\begin{tabular}{|c|c|}
\hline cDNA & Primer Sequences $\left(5^{\prime} \rightarrow 3^{\prime}\right)$ \\
\hline apaf1 & $\begin{array}{l}\text { upper: TCCTAAGCATGTTGTCCCTGTGGAG } \\
\text { lower: TCCGTTTCCAAGTCCCAGAGAACG }\end{array}$ \\
\hline$\beta$-actin & $\begin{array}{l}\text { upper:TGATGGTGGGAATGGGTCAGAAGG } \\
\text { lower: TCACAATGCCTGTGGTACGACCAG }\end{array}$ \\
\hline bclx & $\begin{array}{l}\text { upper: CATCAATGGCAACCCATCCTG } \\
\text { lower: ACTACCTGCTCAAAGCTCTGATACG }\end{array}$ \\
\hline caspase3 & $\begin{array}{l}\text { upper: GAGCACTGGAATGTCATCTCGC } \\
\text { lower: CCACTGTCTGTCTCAATGCCACAG }\end{array}$ \\
\hline cdc2 & $\begin{array}{l}\text { upper: GGAATTGTGTTTTGCCACTCCCG } \\
\text { lower: ATCTCTGAGTCGCCGTGGAAAAGC }\end{array}$ \\
\hline cyclinD1 & $\begin{array}{l}\text { upper: TGCGTGCAGAAGGACATCCAAC } \\
\text { lower: AACACTACCAGTTCCCACTCCAGC }\end{array}$ \\
\hline daxx & $\begin{array}{l}\text { upper: TTCGGGAAAATCGAACCTTGGC } \\
\text { lower: AAAGTCTGAAGGCGATGTGGGACTC }\end{array}$ \\
\hline GAPDH & $\begin{array}{l}\text { upper: TGCATCCTGCACCACCAACT } \\
\text { lower: AACACGGAAGGCCATGCCAG }\end{array}$ \\
\hline $\mathrm{mdm} 2$ & $\begin{array}{l}\text { upper: GACGAGAAGCAGCAGCACATTGTG } \\
\text { lower: CACCAGAATGCTCACTTACGCCAGC }\end{array}$ \\
\hline $\operatorname{tgf}-\beta$-receptor & $\begin{array}{l}\text { upper: AGCATCTACGATGGCTTCCACG } \\
\text { lower: TGCGTCTCTTAAACTTCCTGAGAGC }\end{array}$ \\
\hline ubiquitin & $\begin{array}{l}\text { upper: AGAGTCAACCCTGCACCTGGTCCTC } \\
\text { lower: CACATTCTCGATGGTGTCACTG }\end{array}$ \\
\hline
\end{tabular}

sociated with the failure to implant and continue regular development is poorly understood $(7,10,13,14,29,30)$.

Sensitive RT-PCR protocols available allow the study of expression patterns of individual genes in single blas- tocysts (31). The method reported here provides the possibility of monitoring simultaneously the activities of different apoptotic and metabolic pathways.

Using our model array, we demonstrated that the array analysis of ampli-

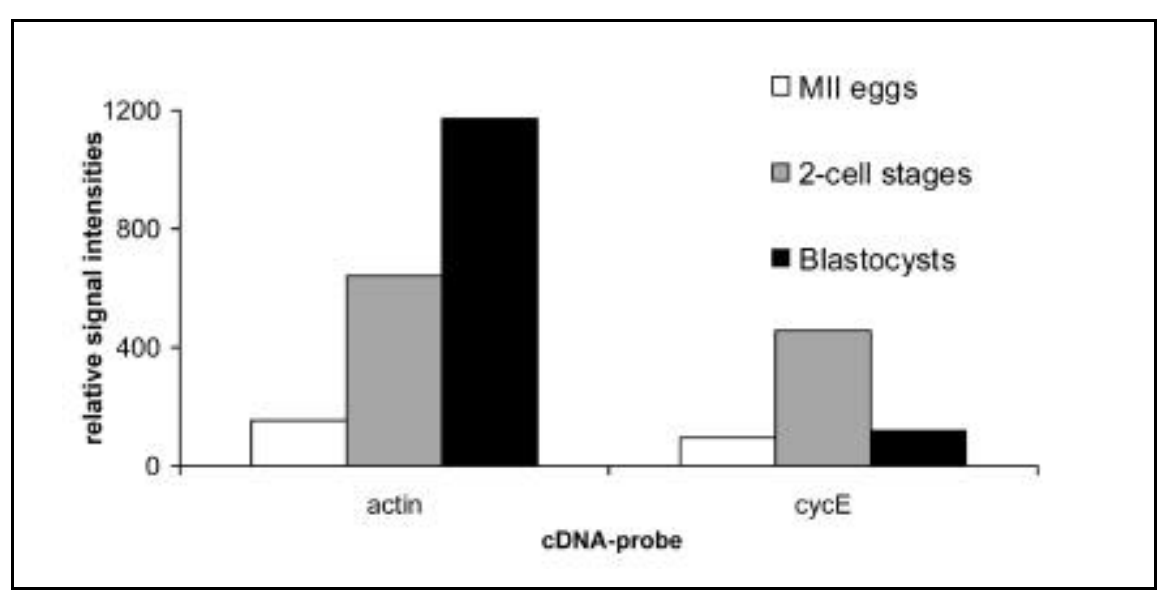

Figure 5. Relative signal intensities obtained from different embryonic stages. Relative signal intensities of the cDNA probes for $\beta$-actin and cyclinE obtained from pools of metaphase II-arrested eggs (white columns), two-cell stages (grey columns), and blastocysts (black columns) are displayed. Signal intensities were normalized to the GAPDH standard value, which was defined as 1000. MII, metaphase II-arrested. 
fied samples permits the investigation of relative transcript levels of housekeeper-, cell-cycle-, and apoptosis-related genes in single preimplantation embryos. We were able to analyze the expression of highly and moderately abundant mRNAs with our model cDNA array system. Further experiments are needed to determine if this method can also be employed to reproducibly detect mRNAs that are expressed at low levels in single embryos. Using more complex arrays in additional experiments will reveal a more detailed insight into the regulatory networks involved in preimplantation development. Thus, cDNA array analysis will be a valuable tool to extend our understanding of the regulatory networks involved in mammalian embryogenesis.

\section{ACKNOWLEDGMENTS}

Funding by Deutsche Forschungsgemeinschaft (SFB 265) is gratefully acknowledged.

\section{REFERENCES}

1.Chee, M., R. Yang, E. Hubbell, A. Berno, X.C. Huang, D. Stern, J. Winkler, D.J. Lockhart, et al. 1996. Accessing genetic information with high-density DNA arrays. Science 274:610-614.

2.Chenchik, A., Y.Y. Zhu, L. Diatchenko, R. Li, J. Hill, and P.D. Siebert. 1998. Generation and use of high-qualitiy cDNA from small amounts of total RNA by SMART TM PCR. In P. Siebert and J. Larrick (Eds.), Gene Cloning and Analysis by RT-PCR. BioTechniques Books, Natick, MA.

3.Cheung, V.G., M. Morley, F. Aguilar, A. Massimi, R. Kucherlapati, and G. Childs. 1999. Making and reading of microarrays. Nat. Genet. 21(Suppl):15-19.

4.Domashenko, A.D., K.E. Latham, and K.S. Hatton. 1997. Expression of myc-family, mycinteracting, and myc-target genes during preim plantation mouse development. Mol. Reprod. Dev. 47:57-65.

5.Duggan, D.J., M. Bittner, Y. Chen, P. Meltzer, and J.M. Trent. 1999. Expression profiling using cDNA microarrays. Nat. Genet. 21(Suppl):10-14.

6.Eberwine, J., H. Yeh, K. Miyashiro, Y. Cao, S. Nair, R. Finell, M. Zettel, and P. Coleman. 1992. Analysis of gene expression in single live neurons. Proc. Natl. Acad. Sci. USA 89:30103014.

7.Exley, G.E., C. Tang, A.S. McElhinny, and C.M. Warner. 1999. Expression of caspase and BCL-2 apoptotic family members in mouse preimplantation embryos. Biol. Reprod. 61:231-239.
8.Harrington, C.A., C. Rosenow, and J. Retief. 2000. Monitoring gene expression using DNA microarrays. Curr. Opin. Microbiol. 3:285-291.

9.Hedge, P., R. Qi, K. Abernathy, C. Gay, S. Dharap, R. Gaspard, J.E. Hughes, E. Snesrud, et al. 2000. A concise guide to microarray analysis. BioTechniques 29:548-562.

10.Hinck, L., P. Van Der Smissen, M. Heusterpreute, I. Donnay, R. De Hertogh, and S. Pampfer. 2001. Identification of caspase-3 and caspase-activated deoxyribonuclease in rat blastocysts and their implication in the induction of chromatin degradation (but not nuclear fragmentation) by high glucose. Biol. Reprod. 64:555-562.

11.Hogan, B., F. Constantini, and E. Lacy. 1986 Manipulating the Mouse Embryo-A Laboratory Manual. CSH Laboratory Press, Cold Spring Harbor, NY.

12.Jurecic, R. and J.W. Belmont. 2000. Longdistance DD-PCR and cDNA microarrays. Curr. Opin. Microbiol. 3:316-321.

13.Kawamura, K., J. Fukuda, H. Kodama, J. Kumagai, A. Kumagai, and T. Tanaka. 2001. Expression of Fas and Fas ligand mRNA in rat and human preimplantation embryos. Mol. Hum. Reprod. 7:431-436.

14.Levy, R. 2001. Genetic regulation of preim plantation embryo survival. Int. Rev. Cytol. 210:1-37.

15.Lockhart, D.J. and E.A. Winzeler. 2000. Genomics, gene expression, and DNA arrays. $\mathrm{Na}-$ ture 405:827-836.

16.Mahadevappa, M. and J.A. Warrington. 1999. A high-density probe array sample preparation method using 10- to 100-fold fewer cells. Nat. Biotechnol. 17:1134-1136.

17.McPherson, M.J. and S.G. Møller. 2000. PCR. BIOS Scientific Publishers Limited, Oxford, UK.

18.Nisson, P.E., S. Francis, and W.R. Crain. 1989. Spatial patterns of gene expression in preimplantation mouse embryos. Mol. Reprod. Dev. 1:254-263.

19.Ohyama, H., X. Zhang, Y. Khono, I. Alevizos, M. Posner, D.T. Wong, and R. Todd. 2000. Laser capture microdissection-generated target sample for high-density oligonucleotide array hybridization. BioTechniques 29:530536.

20.Piko, L. and K.B. Clegg. 1982. Quantitative changes in total RNA, total poly(A), and ribosomes in early mouse embryos. Dev. Biol. 89:362-378.

21.Poirier, G.M.C., J. Pyati, J.S. Wan, and M.G. Erlander. 1997. Screening differentially expressed cDNA clones obtained by differential display using amplified RNA. Nucleic Acids Res. 25:913-914.

22.Pradet-Balade, B., F. Boulmé, E.W. Müllner, and J.A. Garcia-Sanz. 2001. Reliability of mRNA profiling: verification for samples with different complexities. BioTechniques 30:1352-1357.

23. Rambathla, L., B. Pathel, N. Dhanasekaran, and K.E. Latham. 1995. Analysis of G protein $\alpha$ subunit mRNA abundance in preimplnatation mouse embryos using a rapid quantitative RTPCR approach. Mol. Reprod. Dev. 41:314-324.

24.Salunga, R.C., H. Guo, L. Luo, A. Bittner, K.C. Joy, J.R. Chambers, J.S. Wan, M.R. Jackson, et al. 1999. Gene expression analysis via cDNA microarrays of laser capture microdissected cells from fixed tissues, p. 121137. In M. Schena (Ed.), DNA Microarrays. Oxford University Press, New York.

25.Schena, M., D. Shalon, R.W. Davis, and P.O. Brown. 1995. Quantitative monitoring of gene expression patterns with a complementary DNA microarray. Science 270:467-470.

26.Trenkle, T., J. Welsh, and M. McClelland. 1999. Differential display probes for cDNA arrays. BioTechniques 27:554-564.

27.Van Gelder, R.N., M.E. von Zastrow, A. Yool, W.C. Dement, J.D. Barchas, and J.H. Eberwine. 1990. Amplified RNA synthesized from limited quantities of heterogenous cDNA. Proc. Natl. Acad. Sci. USA 87:1663-1667.

28. Vernon, S.D., E.R. Unger, M. Rajeevan, I.M. Dimulescu, R. Nisenbaum, and C.E. Campbell. 2000 . Reproducibility of alternative probe synthesis approaches for gene expression profiling with arrays. J. Mol. Diag. 2:124-127.

29. Warner, C.M., A.S. McElhinny, L. Wu, C. Cieluch, X. Ke, W. Cao, C. Tang, and G.E. Exley. 1998. Role of the Ped gene and apoptosis genes in control of preimplantation development. J. Assist. Reprod. Genet. 15:331-337.

30.Warner, C.M., G.E. Exley, A.S. McElhinny, and C. Tang. 1998. Genetic regulation of preimplantation mouse embryo survival. J. Exp. Zool. 282:272-279.

31.Wrenzycki, C., D. Herrmann, L. Keskintepe, A. Martins, S. Sirisathien, B. Brakett, and H. Niemann. 2001. Effects of culture system and protein supplementation on mRNA expression in pre-implantation bovine embryos. Hum. Reprod. 16:893-901.

32.Zhumabayeva, B., L. Diatchenko, A. Chechnik, and P.D. Siebert. 2001. Use of

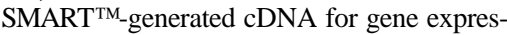
sion studies in multiple human tumors. BioTechniques 30:158-163.

Received 9 November 2001; accepted 16 April 2002.

Address correspondence to:

Prof. Dr. Heiner Niemann

Department of Biotechnology

Institute for Animal Science and Animal Behaviour, Mariensee

Federal Agricultural Research Center

Hoeltystr. 10

31535 Neustadt, Germany

e-mail:niemann@tz.fal.de

For reprints of this or any other article, contact Reprints@BioTechniques.com 